\title{
FORAGING ECOLOGY OF THE LEAF-CUTTING ANT \\ ACROMYRMEX OCTOSPINOSUS \\ IN A COSTA RICAN RAIN FOREST
}

\author{
BY JAMES K. WeTtERER \\ Museum of Comparative Zoology, \\ Harvard University, \\ Cambridge MA 02138
}

\begin{abstract}
INTRODUCTION
Leaf-cutting ants (Tribe Attini: Atta spp. and Acromyrmex spp.) show a high degree of worker size polymorphism with an extensive division of labour among size castes (Wilson, 1980a, b). Foraging is done by medium to large-size workers, who cut and collect plant material which they carry back to the nest. At the nest, smaller workers prepare the retrieved material as a substrate for growing a specialized type of fungus that the ants use for food. One characteristic that distinguishes the two genera of leaf-cutters is that only Atta spp. produce a soldier caste of large workers whose primary function is nest defense (Weber, 1972). In addition, Atta spp. colonies can grow to include several million workers, whereas the largest Acromyrmex spp. colonies have only one hundred thousand workers (Weber, 1972).

In earlier studies, I examined the foraging of Atta cephalotes (L.) at La Selva Biological Station in a Costa Rican rain forest (Wetterer, 1990a, b, 1991, ms). In the present study, conducted in the same forest, I examined the foraging of another common species of leaf-cutting ant, Acromyrmex octospinosus (Reich). Laboratory studies have noted numerous differences between $A c$. octospinosus and A. cephalotes in substrate selectivity (e.g., Littledyke and Cherrett, 1975, 1978, Howard et al., 1989), but did not relate these to any ecological differences between the species. Here, I examined the substrate selectivity, forager mass, and load mass for Ac. octospinosus foragers in the field. I compared these data with the findings from my earlier work with $A$. cephalotes and
\end{abstract}

Manuscript received January 6, 1992 
attempted to identify consistent ecological differences between these two sympatric species of leaf-cutting ants.

\section{Methods}

I collected laden Ac. octospinosus echinatior Forel foragers from along the main foraging trail at five colonies (colonies A-E) on the grounds of the La Selva Biological Station, Puerto Viejo de Sarapiqui, Costa Rica, during both the wet season (July 1989 and June 1991) and the dry season (March-April 1990).

In July 1989, I collected ants at colonies A, D, and E. On returning the following dry season (March-April 1990), I found foraging ants only at colony $\mathrm{E}$, the largest of the colonies. At colony A, I dug into the nest and found the ants still present, but not actively foraging. At this time I collected laden ants at colony $\mathrm{E}$ and at a fourth colony (B). In January and June 1991, I found ants actively foraging at colonies A, B, and E. In June 1991 I made a collection at a fifth colony (C).

At colonies A, B, C, and D, foraging activity averaged three or fewer laden ants per minute, and I collected consecutive ants on the trail. At colony E, however, foraging activity was much higher, averaging about 20 to 50 laden ants per minute throughout the study. Here I collected laden ants at 30 -second intervals as they passed a set point on their trail. I placed each ant with her load in a separate 2-dram vial. I measured fresh mass of each ant and load to the nearest $0.1 \mathrm{mg}$ on a Mettler Balance, and scored each load as fresh (soft, pliant, and green) or fallen (dry or yellowed) leaf material (fragment or whole leaf), herb section (herb stem with or without leaves, leaf buds, or flowers), flower (part or whole), fruit (part or whole berry), or "other." After measurements, I released the ants back on their trails.

\section{RESULTS}

\section{Foraging selectivity}

Ac. octospinosus foragers carried a wide variety of vegetable matter (Table 1), but I never found them cutting leaves of large trees. For all collections except one, fewer than half the laden $A c$. octospinosus foragers carried fresh leaf material. The fresh leaf material that the ants did cut came primarily from soft hairy leaves 
Table 1. Foraging selectivity by five different colonies of Acromyrmex octospinosus (colonies A, B, C, D and E; season: $\mathrm{W}=$ wet, $\mathrm{D}=$ dry; time of foraging: $\mathrm{d}=$ primarily diurnal, $\mathrm{n}=$ primarily nocturnal).

\begin{tabular}{|c|c|c|c|c|c|c|c|c|c|}
\hline colony & (n) & season & time & $\begin{array}{c}\% \text { fresh } \\
\text { leaf }\end{array}$ & $\begin{array}{c}\% \text { fallen } \\
\text { leaf }\end{array}$ & $\begin{array}{l}\% \text { herb } \\
\text { section }\end{array}$ & $\%$ flower & $\%$ fruit & $\%$ other \\
\hline A & (25) & W & d & 24 & 40 & 4 & 4 & 28 & 0 \\
\hline B & (100) & D & $\mathrm{n}$ & 24 & 30 & 17 & 14 & 5 & 10 \\
\hline $\mathrm{C}$ & $(25)$ & W & $\mathrm{n}$ & 8 & 4 & 0 & 36 & 52 & 0 \\
\hline D & $(50)$ & W & $\mathrm{d}$ & 0 & 0 & 0 & 0 & 92 & 8 \\
\hline $\mathrm{E}$ & (50) & W & $\mathrm{n}$ & 22 & 8 & 12 & 52 & 4 & 2 \\
\hline $\mathrm{E}$ & $(25)$ & D & $\mathrm{n}$ & 76 & 8 & 4 & 12 & 0 & 0 \\
\hline
\end{tabular}

of herbs. The foragers also commonly cut whole sections of herbs (herb stems with or without leaves, leaf buds, or flowers). In addition, the foragers cut pieces of fallen leaves, fruit, and petals, and gathered fallen berries, flower buds, and variable amounts of other types of plant material (petioles, twigs, seeds, seed pods, and bark).

Whereas the nests of all five study colonies were located within areas of closed canopy forest, the ants from two colonies (A and B) foraged primarily within the relatively open areas of the laboratory clearing. These two colonies had the highest proportion of dried leaf fragments, probably because fallen leaves dry quickly in open areas and do not decay as readily.

\section{Forager mass}

Mean forager mass varied among Ac. octospinosus colonies (Table 2). For all Ac. octospinosus colonies combined, foragers weighed 4.0 to $21.2 \mathrm{mg}$, a 5.3 -fold range in mass. For any given colony, I found a narrower size-range of foragers, from a 1.7 -fold to a 4.4-fold difference in mass between the smallest and largest forager (mean coefficient of variation $=0.21$ ).

Weber (1972) reported that Ac. octospinosus had workers weighing up to $15.6 \mathrm{mg}$. In the present study, I collected foragers of greater mass than the largest observed by Weber (1972) at four of the five colonies. 
Table 2. Forager polymorphism and load size in Acromyrmex octospinosus. Mean and range of forager mass $\left(m_{\mathrm{A}}\right.$ in $\left.\mathrm{mg}\right)$, coefficient of variation $(\mathrm{CV})$, mean burden $\left(\beta=m_{\mathrm{L}} / m_{\mathrm{A}}\right)$, and the logarithmic relation between ant mass and load mass ( $m_{\mathrm{L}}$ in $\mathrm{mg}$ ). (For colony $\mathrm{E}: \mathrm{W}=$ wet season, $\mathrm{D}=$ dry season.) $*=\mathrm{p}<0.05, * *=\mathrm{p}<$ 0.0001 .

\begin{tabular}{lrrcccl}
\hline colony & \multicolumn{1}{c}{$m_{\mathrm{A}} \pm 1 \mathrm{sd}$} & \multicolumn{1}{c}{ range } & $\mathrm{CV}$ & $\beta \pm 1 \mathrm{sd}$ & $\log m_{\mathrm{L}}$ regression & $\mathrm{R}^{2}$ \\
\hline $\mathrm{A}$ & $8.8 \pm 1.9$ & $4.7-11.9$ & 0.22 & $1.7 \pm 1.4$ & $-0.2+1.2 \log m_{\mathrm{A}}$ & 0.07 \\
$\mathrm{~B}$ & $10.4 \pm 3.0$ & $4.0-17.5$ & 0.28 & $1.0 \pm 0.9$ & $-0.3+1.0 \log m_{\mathrm{A}}$ & $0.06^{*}$ \\
$\mathrm{C}$ & $14.1 \pm 4.4$ & $5.0-19.7$ & 0.32 & $2.0 \pm 1.1$ & $0.6+0.6 \log m_{\mathrm{A}}$ & $0.15^{*}$ \\
$\mathrm{D}$ & $16.4 \pm 2.4$ & $10.8-21.2$ & 0.14 & $1.0 \pm 1.1$ & $0.8+0.2 \log m_{\mathrm{A}}$ & 0.00 \\
$\mathrm{E}(\mathrm{W})$ & $15.7 \pm 2.7$ & $8.2-20.3$ & 0.17 & $2.3 \pm 1.6$ & $0.5+0.8 \log m_{\mathrm{A}}$ & 0.03 \\
$\mathrm{E}(\mathrm{D})$ & $17.9 \pm 2.0$ & $12.0-20.6$ & 0.11 & $1.6 \pm 0.9$ & $1.7-0.2 \log m_{\mathrm{A}}$ & 0.00 \\
& & & & & & \\
Combined & $13.3 \pm 4.2$ & $4.0-21.2$ & 0.31 & $1.4 \pm 1.2$ & $-0.5+1.4 \log m_{\mathrm{A}}$ & $0.16^{* *}$ \\
\hline
\end{tabular}

\section{Load-mass selectivity}

Foragers from individual colonies of Ac. octospinosus showed little or no correlation between ant mass $\left(m_{\mathrm{A}}\right)$ and load mass $\left(m_{\mathrm{L}}\right)$ (Table 2). In part, this is a result of the narrow size range of foragers within a colony. Combining across colonies, however, there was a significant positive correlation between ant mass and load mass (Table 2, Figure 1).

Overall, Ac. octospinosus foragers carried loads that averaged 1.4 times their own mass (burden $\left(m_{\mathrm{L}} / m_{\mathrm{A}}\right)$ range $=0.02-5.8$ ). Only $5 \%$ of the foragers carried loads greater than four times their own mass.

\section{Discussion}

Ac. octospinosus foragers primarily cut the leaves and other parts of small herbs and also scavenged on fallen leaves, fruit and flowers. This foraging selectivity conformed with the qualitative observations of Weber (1945) who reported that Ac. octospinosus in Trinidad cut a wide variety of both fresh and withered vegetation, including flowers and leaves of cacao, fruit and flowers of papaya, and the leaves and flowers of various herbaceous plants. Therrien et al. (1986) also reported that Ac. octospinosus in Guadeloupe cut leaves, flowers, and fruit.

Ac. octospinosus showed striking differences in foraging ecology compared to the sympatric leaf-cutter, A. cephalotes. Although 


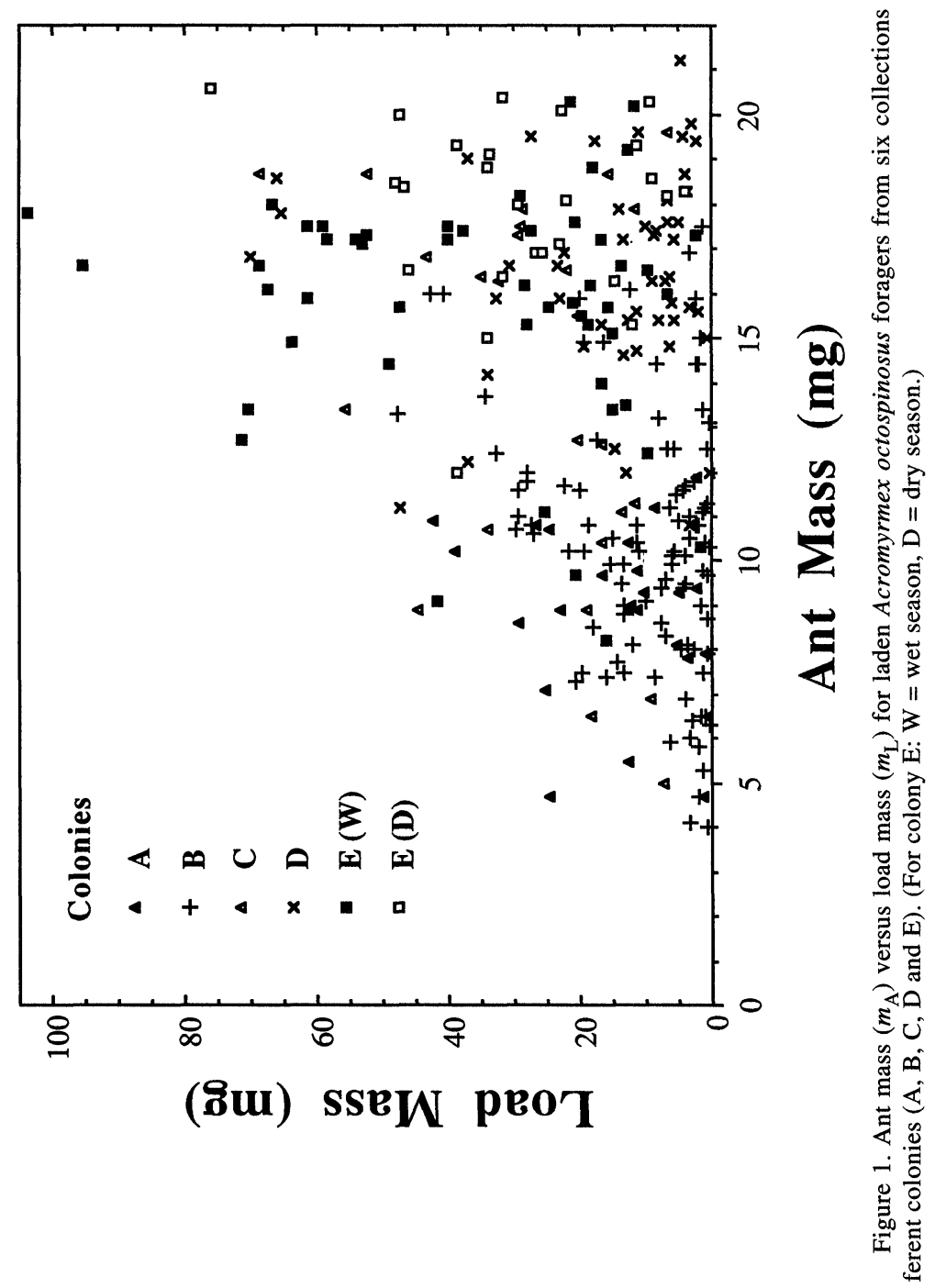


A. cephalotes foragers carried a variety of vegetable matter, the vast majority of the foragers at mature colonies carried fresh leaf fragments, usually cut from large trees (Wetterer, 1990a, ms, personal observation). In the course of seven months at La Selva, only once did I note Ac. octospinosus and A. cephalotes foragers attacking the same resource at the same time. Both species were cutting a large crop of fallen petals. The areas where the two species foraged changed daily, but never overlapped, suggesting possible interference competition.

Compared with A. cephalotes foragers in the same forest, Ac. octospinosus foragers were on average larger and less variable in size. For A. cephalotes at La Selva, the overall mean forager mass was about $7 \mathrm{mg}$ (Wetterer, 1990a, ms), compared with a mean mass of $13.3 \mathrm{mg}$ for Ac. octospinosus foragers in the present study (though the mean mass of $A$. cephalotes foragers attacking single trees varied from 4.2 to $11.1 \mathrm{mg}$ ). Overall, the size of $A$. cephalotes workers commonly foraging ranged about 25 -fold in mass (1.5-35 mg) compared with 5.3-fold range in Ac. octospinosus. In A. cephalotes colonies, foragers of a 5- to 10-fold range of mass $(\mathrm{CV}=0.3-0.7)$ attacked each individual tree (Wetterer, ms), whereas in Ac. octospinosus colonies, a 2- to 4-fold range $(\mathrm{CV}=0.1-0.3)$ attacked two to several different sources.

The overall correlation between ant mass and load mass for $A c$. octospinosus foragers $\left(\mathrm{R}^{2}=0.16\right)$ was lower than typical for $A$. cephalotes foragers coming down trees with fresh leaf fragments $\left(\mathrm{R}^{2}=0.35-40\right.$; Wetterer, 1990a, ms), but at the high end of the range for A. cephalotes foragers picking up abandoned leaf fragments $\left(\mathrm{R}^{2}=0.09-19\right.$; Wetterer, 1990a). In A. cephalotes, much of the match between worker mass and fragment mass results from the geometry of leaf cutting (Wetterer, 1990a, b, 1991). Leaf-cutters anchor their hind feet at the leaf edge while cutting arcs, so larger ants cut larger loads because of their longer hind legs and greater reach (Lutz, 1929; Wetterer, 1991). The pattern of load mass selection by Ac. octospinosus foragers appeared to reflect the mixed nature of their loads which include both fragments cut from fresh and fallen leaves and flowers, as well as other plant material collected from the ground.

Average burden size for Ac. octospinosus foragers ( 1.4 times ant mass) was approximately half as great as the average for $A$. 
cephalotes foragers ( 3 times ant mass; Rudolph and Loudon, 1986, Wetterer, 1990a, ms). This difference appears to be related to several factors. First, Ac. octospinosus foragers were on average larger than A. cephalotes foragers, and in A. cephalotes mean burden decreases with ant mass. Equivalent-size A. cephalotes foragers (13-mg) carried mean loads only $\sim 2.5$ times ant mass (Wetterer, ms). Also, Ac. octospinosus workers have shorter hind legs than A. cephalotes foragers of equivalent mass (Wetterer, 1992) and this may reduce their reach and thus the area of fragments they cut. Finally, Ac. octospinosus foragers collect a higher proportion of dried material, which tends to weigh less due to water loss (Wetterer, 1990a).

The differences in the mass of foragers between the two species may represent different foraging strategies that allow efficient harvesting of each species' preferred vegetation resources. The highly polymorphic A. cephalotes foragers often mass recruit to large trees in prolonged attacks lasting up to several days. In these attacks, the mass of foragers recruited to the leaf source is adjusted to the thickness and toughness of the leaves (Nichols-Orians and Schultz, 1989; Wetterer, 1990a, ms). A similar foraging pattern appears to occur in A. sexdens (L.) (Wilson, 1980b) and A. texana (Buckley) (Waller, 1986, 1989). The match of forager mass to leaf type increases both cutting efficiency (Wilson, 1980b) and transport efficiency (Wetterer, ms). Extreme polymorphism among foragers broadens the diversity of tree species that can be exploited efficiently.

Recruiting workers of different sizes to different sites, however, may be economically beneficial only for sustained attacks on large but variable sources of vegetation such as the leaves of canopy trees. For species such as Ac. octospinosus that depend primarily on cutting or collecting vegetation at small or ephemeral sources, matching worker size to resource type during short duration attacks on individual sources may be economically impractical. A larger, more generalized, and relatively monomorphic forager caste that can harvest vegetation at all encountered sources may be more efficient. Similarly, Ac. versicolor (Pergande) in Arizona, which depends heavily on the leaves of small herbs and dry vegetation collected from the ground, shows little forager polymorphism (S. Rissing, pers. comm.). 
In addition to the wide size range of foragers, $A$. cephalotes colonies also have large $(35-110 \mathrm{mg})$ and generally non-foraging soldier workers patrolling their trails, as well as small (usually $<3$ $\mathrm{mg}$ ) "hitchhiking" workers riding on the leaf fragments carried by other workers. These "hitchhikers" have been shown to protect the foragers from attack by parasitic phorid flies (Feener and Moss, 1990). Although Ac. octospinosus colonies had neither soldiers nor hitchhikers, I found an abundance of non-foraging workers below $3 \mathrm{mg}$ in mass in all Ac. octospinosus colonies that I have dug up (Wetterer, unpublished). Interestingly, Ac. octospinosus foragers were much more "timid" than A. cephalotes foragers, i.e., when disturbed Ac. octospinosus foragers would freeze, drop their loads, and/or run off the trail and hide. Such defensive behavior may be related to their lack of soldiers and hitchhikers for protection (see Hunt, 1983).

The ecologies of Ac. octospinosus and A. cephalotes also differ in several other ways. Mature Ac. octospinosus colonies have fewer than one hundred thousand workers whereas A. cephalotes colonies may have several million workers (Weber, 1972). Ac. octospinosus and A. cephalotes also differ in their spatial orientation behavior (see discussion in Wetterer et al., 1992). preliminary data (Wetterer, unpublished) indicates that Ac. octospinosus foragers use more flexible cutting rules than $A$. cephalotes foragers (also see Roces, 1990).

Not all species in the genus Acromyrmex follow the same foraging strategy as Ac. octospinosus. For example, in Sao Paulo State, Brazil, I observed colonies of Ac. niger (F. Smith) in secondary forest with foragers of a wide range of body mass ( $>10$-fold range) attacking the leaves of large trees (personal observation). Hitchhikers on the leaves were fairly common at these colonies. Why Ac. octospinosus does not have hitchhikers is unclear.

Mean forager mass varied among the different Ac. octospinosus colonies. Part of this variation may be related to colony size. In $A$. cephalotes, small colonies ( $<400$ workers) tend to have few or no large workers (Wilson, 1983). As a colony increases in size, however, it often expands its worker size range Differences in mean forager mass among leaf-cutter colonies of the same size may represent adjustment of worker production to match available resources or a response to other factors such as the local 
abundance of parasites and predators (see discussion in Wetterer, 1990a).

\section{SUMMARY}

I compared the foraging ecology of the leaf-cutting ant Acromyrmex octospinosus echinatior in Costa Rican rain forest with information from other studies of the sympatric leaf-cutter, $A$. cephalotes. Ac octospinosus foragers primarily cut the leaves and other parts of small herbs and scavenged on fallen leaves, fruit, flowers, and other plant material. In contrast, the vast majority of A. cephalotes foragers carried fresh leaf fragments, usually cut from large trees. Compared with A. cephalotes, Ac octospinosus foragers were on average larger, had a narrow range of body mass, and carried smaller loads relative to their body mass.

The differences between the two species in the mass of foragers may represent different foraging strategies that allow each species to harvest efficiently its preferred vegetation resources. The wide size range of $A$. cephalotes foragers allows different size workers, who specialize on leaves of different thickness and toughness, to exploit fresh leaves of a great variety of trees. The narrow size range of large Ac. octospinosus foragers may be more suited to generalist foragers, able to cut or collect any desirable vegetation encountered.

\section{ACKNOWLEDGEMENTS}

I thank M. Wetterer, L. Keller, D. Waller, and J. Howard for comments on this manuscript. Financial support was provided by the Organization for Tropical Studies, the Jesse Smith Noyes Foundation, the American Philosophical Society, and the National Science Foundation (grants BSR 8906869 to S. Hubbell and BSR 9103782 to J. Wetterer).

\section{Literature Cited}

FEENER, D. H. JR. AND K. A. G. Moss

1990. Defense against parasites by hitchhikers in leaf-cutting ants: a quantitative assessment. Behavioral Ecology and Sociobiology 26: $17-29$.

Howard, J. J., T. P. GReEn AND D. F. Weimer

1989. Comparative deterrency of two terpenoids to two genera of attine ants. Journal of Chemical Ecology 15: 2279-2288. 
HuNT, J. H.

1983. Foraging and morphology in ants: the role of vertebrate predators as agents of natural selection. pp. 83-104 in Social Insects in the Tropics, vol. 2 (ed. P. Jaisson) Univ. Paris-Nord, Paris.

LitTLEDyke, M. AND J. M. CherRetT

1975. Variability in the selection of substrate by the leaf-cutting ants Atta cephalotes (L.) and Acromyrmex octospinosus (Reich) (Hymenoptera: Formicidae). Bulletin of Entomology Research 65: 33-47.

1978. Defence mechanisms in young and old leaves against cutting by the leaf-cutting ants Atta cephalotes (L.) and Acromyrmex octospinosus (Reich) (Hymenoptera: Formicidae). Bulletin of Entomology Research 68: $263-271$.

LuTZ, F. E.

1929. Observations on leaf-cutting ants. American Museum Novitates 388: $1-21$.

Nichols-Orians, C. M. AND J. C. Schultz

1989. Leaf toughness affects leaf harvesting by the leaf-cutter ant, Atta cephalotes (L.) (Hymenoptera: Formicidae). Biotropica 21: 80-83.

Roces, F.

1990. Leaf-cutting ants cut fragment sizes in relation to the distance from the nest. Animal Behaviour 40: 1181-1183.

RUDOLPH, S. G. AND K. LOUdON

1986. Load size selection by foraging leaf-cutter ants (Atta cephalotes). Ecological Entomology 11: 401-410.

Therrien, P., J. N. McNeil, W. G. Wellington, and G. Febvay

1986. Ecological studies of the leaf-cutting ant Acromyrmex octospinosus, in Guadeloupe. pp. 172-183 in Fire Ants and Leaf-cutting Ants (ed. C. Lofgren and R. Vander Meer). Westview Press, Boulder, CO.

WALLER, D. A.

1986. The foraging ecology of Atta texana in Texas. pp. 146-158 in Fire Ants and Leaf-cutting Ants (ed. C. Lofgren and R. Vander Meer). Westview Press, Boulder, CO.

1989. Size-related foraging in the leaf-cutting ant Atta texana (Buckley) (Formicidae: Attini). Functional Ecology 3: 461-468.

WEBER, N. A.

1945. The biology of the fungus-growing ants. Part VIII. The Trinidad, B. W. I., species. Revista de Entomologia 16: 1-88.

1972. Gardening ants: the attines. American Philosophical Society. Philadelphia, PA.

WETTERER, J. K.

1990a. Diel changes in forager size, activity, and load selectivity in a tropical leaf-cutting ant, Atta cephalotes. Ecological Entomology 15: 97-104.

1990b.Load-size determination in leaf-cutting ants. Behavioral Ecology 1: 95-101.

1991. Allometry and the geometry of leaf-cutting in Atta cephalotes. Behavioral Ecology and Sociobiology 29: 347-351.

1992. Nourishment and evolution among fungus-growing ants and their fungi. In press, Nourishment and Evolution in the Social Insects. (ed. J. H. Hunt and C. Nalepa). Westview Press, Boulder, CO. 
ms. Worker polymorphism in the leaf-cutting ant, Atta cephalotes: the match of forager mass to leaf density. Submitted to Animal Behaviour.

Wetterer, J. K., S. Shafier, L. Morrison, K. Lips, G. Gilbert, M. Cipollini, \& C. BLANEY

1992. On- and off-trail orientation in the leaf-cutting ant, Atta cephalotes. Journal of the Kansas Entomological Society 65: 96-98.

WILSON, E. O.

1980a. Caste and division of labor in leaf-cutter ants. I. The overall pattern in A. sexdens. Behavioral Ecology and Sociobiology 7: 143-156.

1980b. Caste and division of labor in leaf-cutter ants. II. The ergonomic organization of leaf cutting. Behavioral Ecology and Sociobiology 7: 157-165.

1983. Caste and division of labor in leaf-cutter ants. IV. Colony ontogeny of A. cephalotes. Behavioral Ecology and Sociobiology 14: 55-60. 

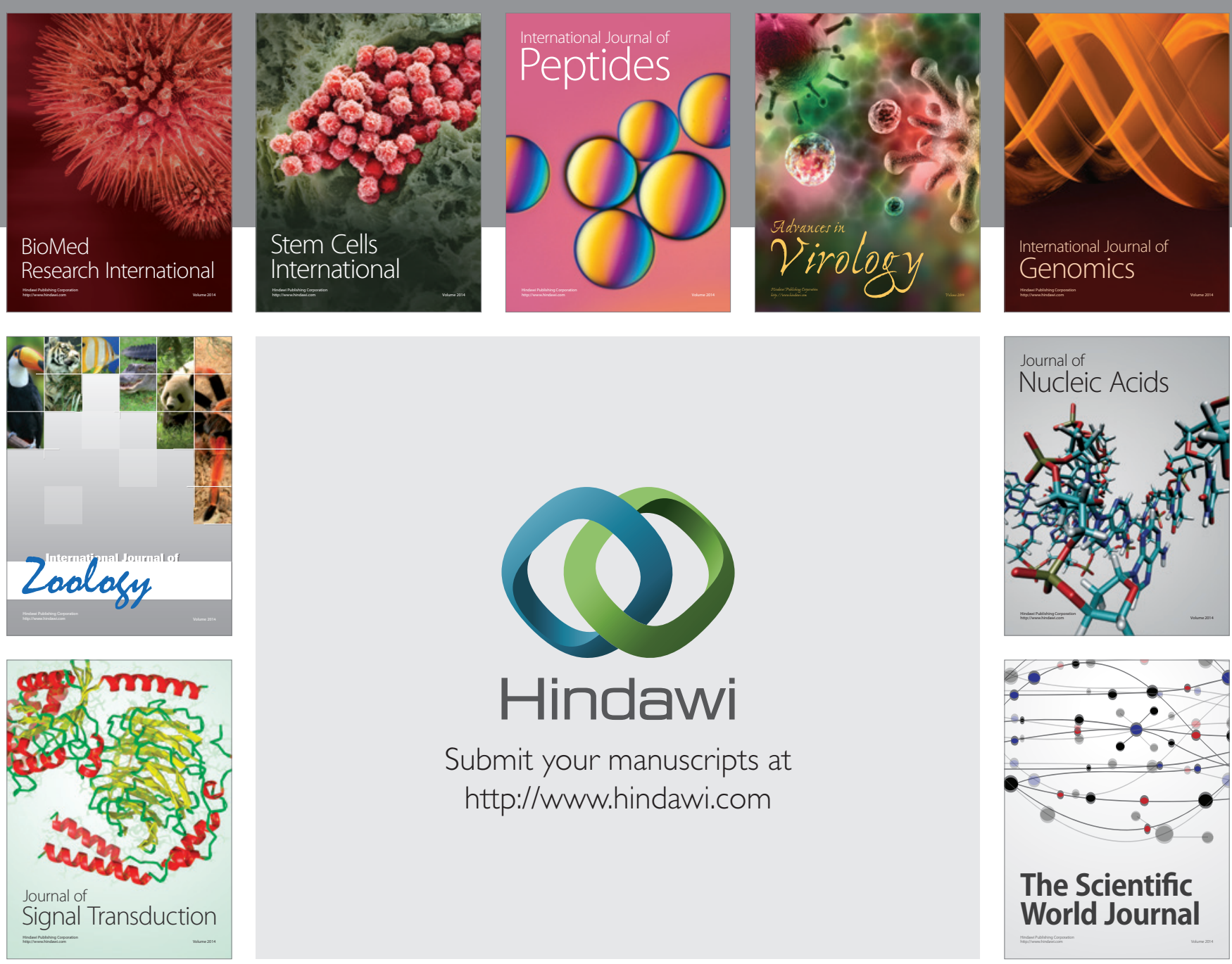

Submit your manuscripts at

http://www.hindawi.com
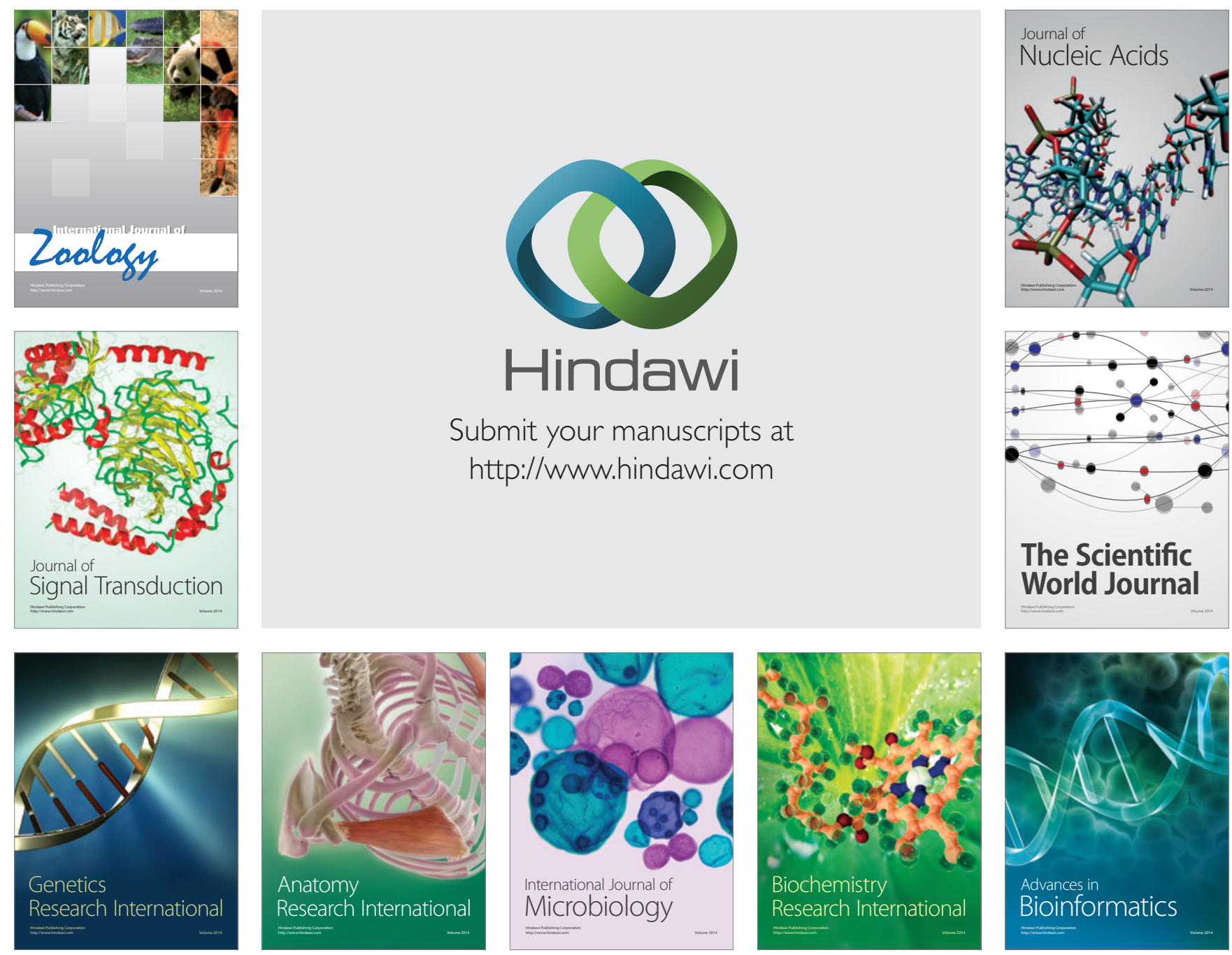

The Scientific World Journal
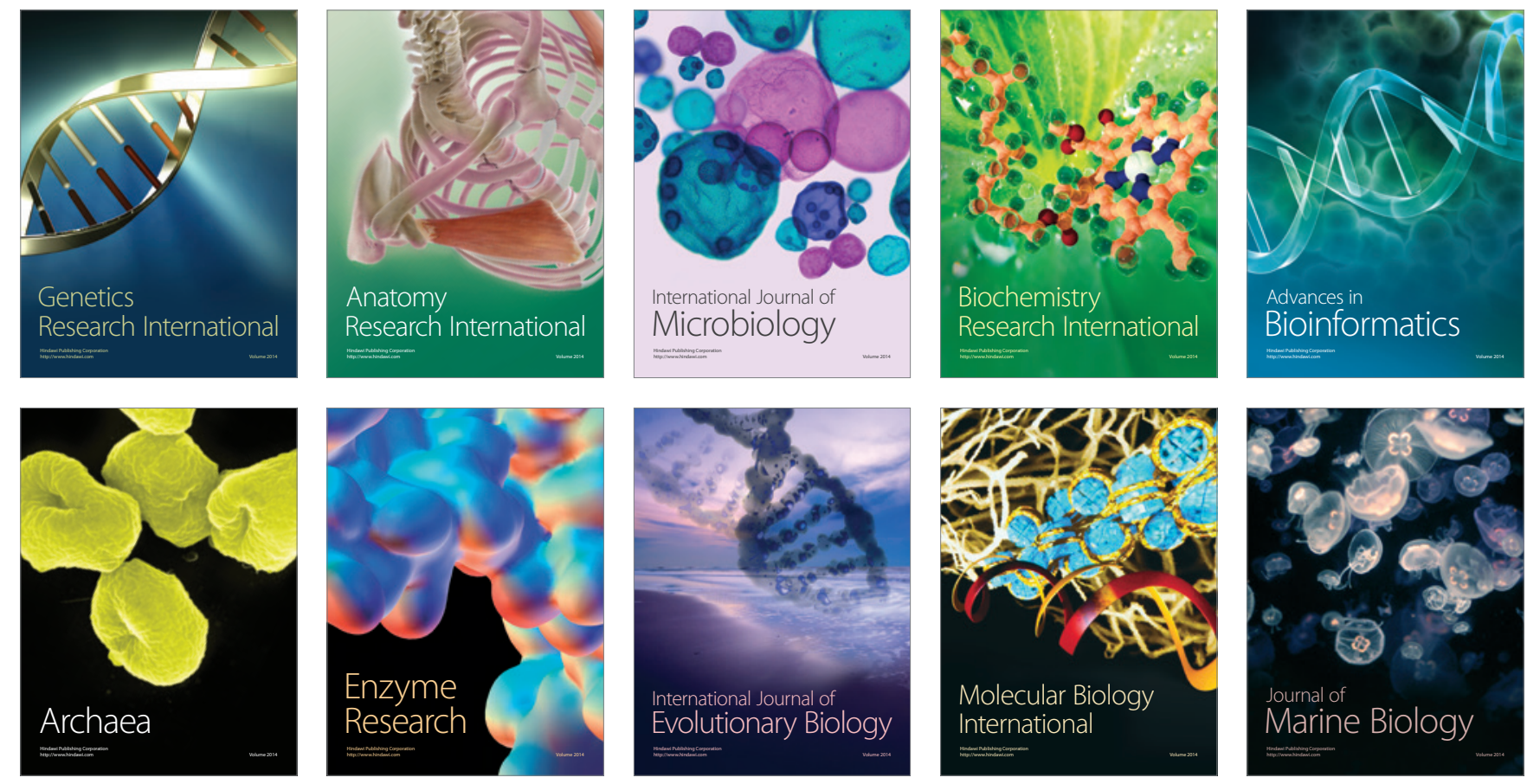